Music Education Research

\title{
Some considerations on research dissemination with particular reference to the audience and the authorship of papers
}

\section{Oscar Odena}

To cite this article: Oscar Odena (2004) Some considerations on research dissemination with particular reference to the audience and the authorship of papers, Music Education Research, 6:1, 101-110, DOI: $10.1080 / 1461380032000182876$

To link to this article: http://dx.doi.org/10.1080/1461380032000182876

$$
\text { ( ) } 2004 \text { The Author(s). Published by Taylor \& }
$$

\section{曲 Published online: 23 Jan 2007.}

Submit your article to this journal ๘

\section{Article views: 122}

Q View related articles $๘$

Citing articles: 4 View citing articles $ऍ$ 


\title{
VIEWPOINTS
}

\section{Some considerations on research dissemination with particular reference to the audience and the authorship of papers}

\author{
Oscar Odena ${ }^{\star}$ \\ Escola Superior de Música de Catalunya, Barcelona, Spain
}

\begin{abstract}
This paper suggests that some refinements might need to be considered to current codes of ethics for dissemination of research. The growth of research in music education over the last decade is reviewed, with examples from new journals, conferences and professional associations. It is argued that nowadays researchers have to address a multidisciplinary number of audiences and this should be taken into account in the regulations for conferences and publications with the incorporation of guidelines for contributors to address their specific audience and to explain any previous dissemination. The authorship of papers is also considered, in particular issues arising from multiple authorship, as well as the research participants' contribution to the final report. Some of these issues are discussed with reference to studies focussed on a particular topic (creativity in music education) within the context of music education research, but it is acknowledged that the discussion also applies to other fields of the humanities and social sciences.
\end{abstract}

\section{Introduction: the recent growth of music education research}

During the last decade, there has been an increase in research focussed on creativity in music education. This has been reflected in several special symposiums at research conferences, such as those organized by the Society for Education, Music and Psychology Research (SEMPRE, formerly the Society for Research in Psychology of Music and Music Education [SRPMME]), the European Society for the Cognitive Sciences of Music (ESCOM), and the biannual International Conference of Research in Music Education (RIME). The interest in creativity and music education has also been evident from the number of articles published in journals by English-speaking scholars, including Brinkman (1999), Burnard (1999, 2002), Berkley (2001), MacDonald and Miell (2000), Byrne and Sheridan (2001), and Savage (2003). It may be argued that increased research in this field coincided with

^Department of Pedagogy, Escola Superior de Música de Catalunya, Berenguer de Palou 104-118, 08027 Barcelona, Spain. Email: oscar.odena@esmuc.net

ISSN 1461-3808 (print)/ISSN 1469-9893 (online)/04/010101-10

$r$

DOI: $10.1080 / 1461380032000182876$

(C) 2004 The Author(s) . Published by Taylor \& Francis

This is an Open Access article distributed under the terms of the Creative Commons Attribution License (http://creativecommons.org/licenses/by/4.0/), which permits unrestricted use, distribution, and reproduction in any medium, provided the original work is properly cited. 
a rising number of research studies in several other areas of music education. Indeed, the number of academic journals on music education has grown in the last decade, with the incorporation of new titles: Quarterly fournal of Music Teaching and Learning (1990), Research Studies in Music Education (1993), Philosophy of Music Education Review (1993), Music Education Research (1999), Fournal of Historical Research in Music Education (1999), and Music Education International (2002). This increasing research has been documented by the British Educational Research Association in the document Mapping music education research in the UK (BERA, 2001). The pace of development of music education research has also been outlined by Hanley and Montgomery (2002) and Hickey (2002) in The new handbook of research on music teaching and learning, published by the American National Association for Music Education (Colwell \& Richardson, 2002).

Although these developments will be regarded by music educators as encouraging, it is necessary to recognize that research in music education is still fairly limited in comparison with other areas; for a long time it was a minor field in the university-led arena of educational research. The recent formation of a Special Interest Group (SIG) on Music Education within the American Educational Research Association (AERA), the biggest professional association of its kind, is an indication that music educators are more concerned with research than they were previously.

\section{Addressing multiple audiences}

In the current context, multiple audiences have developed, and researchers need to engage with them if they wish to increase the dissemination of their work. Examples of this multiple dissemination can be found in recent conference proceedings, articles and books. For instance, Burnard has written several articles and papers concerning her study of pupil's compositions and improvisations (e.g. Burnard, 1999, 2000a, b, 2001, 2002, 2003), all of which report on different conceptual slices of a large project and are addressed to the particular audience of the conference or journal in which they were presented or published. Hence, the audience seems to be an important issue to take into account, which is not often considered in the codes of ethics for dissemination of research. For instance, the code of ethics for research publication/presentation of the American National Association for Music Education includes the following statement:

\footnotetext{
Papers submitted for presentation via any format (i.e. posters, paper-reading sessions) should not have been presented at another major conference. If the data have been presented in whole or substantive part in any forum, in print, or at previous research sessions, a statement specifying particulars of the above must be included with the submission. (MENC, 1998, paragraph 6)
}

This code of ethics is based on the manual of the American Psychological Association (1994) and the 'Ethical Principles of Psychologists'-published in 1981 in American Psychologist, number 36. The MENC's guidelines are taken as an example by journals (Fournal of Research in Music Education) and major conferences in the field, such as the seminars of the Research Commission of the International Society 
for Music Education (ISME), but given that several associations exist (e.g. ISME, AERA, ESCOM, SEMPRE), with their particular audiences, strengths and geographical locations, it would be reasonable to assume that, as long as the audience is properly taken into account, an investigation should be able to be reported in more than one major conference. Referring to this multiplicity of professional associations, the former Chair of the ISME Research Commission observed:

\begin{abstract}
Although it would be relatively simple, hypothetically, to set up an 'International Society for Research in Music Education' by drawing on different membership networks and activities, this could create a 'Chinese wall' between research and practice. This separation is something that we actively strive against. Our intention is always to foster evidence/research-based practice as well as basic research within our particular 'learning community'-a community that should be seen as representing neither an 'activity', nor a 'sector', but is rather a multi-faceted, multidisciplinary, intercultural grouping that shares a multiplicity of interests under the research umbrella. (Welch, 2002, paragraph 10)
\end{abstract}

Hargreaves (2002) pointed out that when delivering conference papers one had to take into account the professional practices of the audience and in so doing change the emphasis of the communication, whether they were educators, psychologists or musicologists. In fact, the dissemination of studies in more than one conference is a fairly common practice, and authors sometimes present abridged versions of their books in the form of papers. As long as this is openly acknowledged (e.g. Green $2001 \mathrm{a}, \mathrm{b}, 2003)$ there is no reason why this should be censored when the message disseminated can be of great value for music educators, and when one of the aims of our music education culture should be this (i.e. communication).

In my own case, aspects of an investigation of teachers' perceptions of creativity in music education (Odena, 2001a, b, 2003) were presented to a mainly British audience at a BERA conference and to a European audience at the Annual Conference of the European Educational Research Association (EERA). At the first conference, it was necessary to comply with the guidelines of a seminar organized by the BERA Special Interest Group 'Creativity in Education'-relating the discussion of findings to the research field of creativity in education (Odena, 2001c). At the EERA conference, the European dimension and the methodological focus of the seminar, organized by the EERA Ethnography Network, had to be taken into account (Odena, 2002), whereas at the RIME 2001 Conference, other aspects of the same project were discussed with the stress on music education matters (Odena, 2001d).

\title{
Issues of authorship
}

Another sensitive topic in the dissemination of research is the acknowledgment of authorship. The Code of Ethics referred to earlier states the following:

Authorship is reserved to those who make major contributions to the research. Credit is assigned to those who have contributed to a publication in proportion to their professional contributions. Major contributions of a professional character, 
made by several individuals to a common project are recognized by joint authorship with the individual who made the principal contribution listed first. (MENC, 1998, paragraph 4)

From this quotation, it can be interpreted that research assistants and postgraduate students that participate in research projects would be included in the authorship. Nevertheless, when referring to the individuals 'who make major contributions to the research', research assistants and students are not mentioned. This is not to suggest that Ph.D. supervisors appropriate their students' research without acknowledgment but rather, that large and long-term projects are often reported by the main academics that contributed. Totterdell (2003) supports the involvement of research students in activities likely to lead to the generation of intellectual property. In addition, he suggests that there should be a serious conversation between student and supervisor from the first year of supervision regarding the future use of the student's project. He observes that his experience of major conferences and research culture in Australia and America (e.g. Bubb et al., 2003) is that the work of doctoral students and research assistants seems to be more openly used, regulated and acknowledged than in the UK context-see for example the documents by the Australian National University (1999) and the Australian Vice Chancellor's Committee (2002). This situation, he argues, enriches the research culture of these associations.

The data from postgraduate students' investigations needs to be acknowledged by anyone using it, especially those who work in the academy. In this way, both students and academics can engage in an intellectual dialogue that is enriching and can open paths for further research. Examples of this interaction are the investigations by Hentschke (1993), Stavrides (1995), Lennon (1996), Silva (1998), Papapanayiotou (1998) and Markea (2002). These studies, which were supervised by Keith Swanwick, fed from Swanwick's earlier work and at the same time tested some of his ideas in different educational settings. For example, Lennon (1996) and Markea (2002) used Swanwick's musical development theories to analyse piano teachers' thinking on practice, in Ireland and Greece respectively. Silva (1998) used them to assess musical understanding across various modalities of music making (composing, performing and audience-listening). Swanwick (1999, 2001) then referred to some of these research results when developing his later work. These intellectual dialogues sometimes crystallized in combined authorship of papers (Swanwick \& Françca, 1999).

An additional issue to consider, particularly in qualitative studies focussed on a small number of individuals, is the involvement of participants in the dissemination of research. This is discussed very little in current research in music education. Following the standard codes of ethics in the Social Sciences-such as the ones by the British Psychological Society (BPS, 2000), BERA (1992), British Sociological Association (BSA, 2002) and the guidelines of research methods manuals (e.g. Cohen et al., 2000)-the identities of participants in educational research are often automatically undisclosed, unless the researcher investigates his or her own practice (action-research). For example, the latest guidelines of the British Psychological Society present the following recommendation: 
[The researcher] shall endeavour to communicate information through research or practice in ways that do not permit the identification of individuals or organizations.

(BPS, 2000, p. 4)

and the guidelines of the British Educational Research Association (1992) state:

[The] right to remain anonymous...should be respected when no clear understanding to the contrary has been reached. Researchers are responsible for taking appropriate precautions to protect the confidentiality of both participants and data. (BERA, 1992, paragraph 13)

In this way, sharing the data and the analysis with participants is not often discussed, ruling out any possibilities of dissemination of research with them, for instance presenting papers at conferences. This may perhaps increase the feeling of 'Chinese wall' between research and practice. For example, music teachers attending a major conference commented to the author that they could 'hardly draw implications for practice' from some of the papers which did not include 'the views of the individuals involved in the research'. Upitis (1999, p. 220) advocates that researchers should be sharing their work 'with audiences far beyond those who live and work in the academy'. Encouraging research participants to get involved at the dissemination stage could facilitate such process.

A recent article by Rex et al. (2002) shows that even participants can be acknowledged as authors when they have a substantial contribution in the final report. Their article illustrates to what extent the teachers' pedagogical stories shape the students' classroom participation and performance, focussing on two teachers of English literature and their classrooms. At the outset, the two teachers (Hobbs and McEachen) and the university researchers (Rex and Murnen) agreed to share the data and the analysis to serve their professional purposes, and they also agreed that 'all four voices would be represented in any publications based on the data' (Rex et al., 2002, p. 795). To this end, a section is included in the paper with the teachers' response of the researchers' analysis, providing their own perspectives of the investigation. These are then taken into account in the final discussion of implications by the researchers.

\section{Conclusion: some suggestions to consider in codes of ethics for research dissemination}

If one of the aims of music education research conferences and journals is to disseminate the results of studies amongst a multifaceted and growing research community, it would be reasonable to assume that their guidelines for participation give further consideration to the sensitive issues discussed here: the current multiplicity of audiences and the authorship of papers.

For the dissemination of reports to multiple audiences, combined authorships have been used to present data from previous research. For instance, Burnard and Younker $(2001,2002)$ presented a combined paper of some aspects of their investigations on creativity in composition, discussing sets of data from their previous studies in Canada, UK and Australia. In fact combining data from different 
investigations, some of which might have been presented elsewhere, is a frequent practice in educational research (e.g. LeBlanc et al., 2002). This would need to be encouraged, especially when the datasets come from different countries, given the apparent benefits of comparative research. Lepherd (1995, p. 3) observes that the study of different educational systems and practices offers music educators 'a broader perspective within which they can assess and attempt to resolve their own problems'. Re-examination of existing data drawn from a range of previous studies has been recognized as a good exercise in educational research:

It is only by drawing upon and drawing together the findings from each other's work that a synthesis of research in a particular area can begin to influence and improve music teaching practice in the way that it should. (Stevens, 2000, p. 72)

Burnard and Younker (2002, pp. 248-249) observed that reusing the same data from a variety of datasets from their earlier projects for further interrogation 'offered the opportunity to construct links between findings, conceptual frameworks and theoretical positions developed from them'. In fact, as long as some basic information such as the origin of the data, the context in which it was collected and the authorship of the original study is disclosed, researchers should be allowed to present 'new research from old data' without restrictions, always taking into account the particular audience to be addressed.

Consequently addressing the audience and the previous dissemination of studies would need to be considered further in the codes of ethics and the calls for papers for conferences and journals, which might need to incorporate specific guidelines to report these issues. For example a statement encouraging authors to submit 'new research from old data' and a further statement explaining the type of public of the conference or journal and how to write for them. Regarding the authorship of papers, it has been suggested that those who make significant contributions to the research process - including research assistants and postgraduate students-need to be acknowledged in the reports. The discussion in this paper has been focused within the context of music education research. Nevertheless, a glance through the catalogues of international publishers and the Internet shows that these matters are also relevant to other areas of the humanities and the social sciences, due to the increasing number of new journals and research conferences. This situation has been accentuated by the rising number of new journals published exclusively online.

A further issue has been discussed concerning the participants of research projects. Although ethic protocols advise researchers to protect the participants' identity, in some qualitative studies where a small number of persons are involved the confidentiality could be negotiated individually with them. They could then use the data and its analysis to serve their professional purposes. For example, in investigations where educational settings are observed (e.g. for the study of studentteacher interactions, musical development or musical creativity) there would be no apparent ethical reason to keep the identity of particular teachers confidential, if they agreed to do so. In addition, if prospective participants (music teachers) were willing to share the analysis of the data, their point of view from both the practice perspective and the research process experience could be incorporated into the final 
analysis. They would then be able to share the research dissemination with the researchers, which in turn might increase the impact of research on practice. Invitations for researchers to share where possible the research dissemination with participants could be included in the codes of ethics, and this would surely enrich the overall experience of delegates at major conferences, benefiting our music education 'learning community'.

\section{Acknowledgements}

My grateful thanks to Michelle Grady for proofreading the original paper. I would also like to thank the students and staff at the School of Arts and Humanities and at the Doctoral School of the University of London Institute of Education for their support and encouragement. Thanks to Rena Upitis for her prompt answer to a late query, and to both anonymous reviewers for their constructive comments. Finally, I would like to thank Lucy Young for endless support.

\section{Notes on contributor}

Oscar Odena studied Psychopedagogy and Music Education at the University of Lleida and a piano teaching degree at the Conservatory of Lleida, Spain. He holds a Master's from Glasgow University and recently completed a Ph.D. focused on English teachers' perceptions of creativity in music education at the University of London, Institute of Education. He has presented papers at several international conferences, is a member of the editorial team of Educate The London Fournal of Doctoral Research in Education and lectures at the Department of Pedagogy of the Higher School of Music of Catalonia, Barcelona.

\section{References}

American Psychological Association (APA) (1994) Publications manual (4th edn) (Washington DC, APA).

Australian National University (1999) Intellectual Property Guidelines-1281E/1998. Available online at: www.anu.edu.au/admin/chairbtf/documents/ippol2.htm

Australian Vice Chancellor's Committee (2002) Ownership of intellectual property in universities: policy and good practice guide. Available online at: www.avcc.edu.au/news/public_statements/publications

Berkley, R. (2001) Why is teaching composing so challenging? A survey of classroom observation and teachers' opinions, British Fournal of Music Education, 18(2), 119-138.

Brinkman, D. J. (1999) Problem finding, creativity style and the musical compositions of high school students, fournal of Creative Behavior, 33(1), 62-68.

British Educational Research Association (BERA) (1992) Ethical guidelines. Available online at: www.bera.ac.uk/guidelines.html

British Educational Research Association (BERA) (2001) Mapping music education research in the UK (London, BERA).

British Psychological Society (2000) Code of conduct, ethical principles and guidelines. Available online at: www.bps.org.uk/documents/Code.pdf 
British Sociological Association (2002) Statement of ethical practice. Available online at: www.britsoc.org.uk

Bubb, S. A., Totterdell, M. and Earley, P. (2003) Accountability and control: 'rogue' principals and schools' responsibilities to new teachers, paper presented at the Annual Conference of the American Educational Research Association 2003, Chicago, IL, 25 April.

Burnard, P. (1999) Bodily intention in children's improvisation and composition, Psychology of Music, 27(2), 159-174.

Burnard, P. (2000a) How children ascribe meaning to improvisation and composition: rethinking pedagogy in music education, Music Education Research, 2(1), 7-23.

Burnard, P. (2000b) Examining experiential differences between improvisation and composition in children's music-making, British fournal of Music Education, 17(3), 227-245.

Burnard, P. (2001) Examining children's musical interaction in improvisation, National Association of Music Educators (NAME) Magazine, 7, 39-43.

Burnard, P. (2002) Investigating children's meaning-making and the emergence of musical interaction in group improvisation, British fournal of Music Education, 19(2), $157-172$.

Burnard, P. (2003) Children's creative thinking: models and metaphors for thinking about curriculum reform in music education, in: L. Yip, Ch. Leung \& W. Lau (Eds) Curriculum innovation in music. Proceedings of the 4th Asia-Pacific Symposium on Music Education Research (Hong Kong, Department of Creative Arts, The Hong Kong Institute of Education).

Burnard, P. \& Younker, B. A. (2001) Mapping pathways: fostering creativity in composition, paper presented at the 2nd International Conference for Research in Music Education, University of Exeter, 4 April.

Burnard, P. \& Younker, B. A. (2002) Mapping pathways: fostering creativity in composition, Music Education Research, 4(2), 245-261.

Byrne, C. \& Sheridan, M. (2001) The Scarlatti papers: development of an action research project in music, British fournal of Music Education, 18(2), 173-185.

Cohen, L., Manion, L. \& Morrison, K. (2000) Research methods in education (5th edn) (London, Routledge).

Colwell, R. \& Richardson, C. (Eds) (2002) The new handbook of research on music teaching and learning (Oxford, MENC/Oxford University Press).

Green, L. (2001a) What can formal music educators learn from popular musicians?, paper presented at the 2nd International Conference for Research in Music Education, University of Exeter, 4 April.

Green, L. (2001b) How popular musicians learn. A way ahead for music education (London, Ashgate).

Green, L. (2003) Informal popular music learning practices and their relevance for formal music educators, in: L. Yip, Ch. Leung \& W. Lau (Eds) Curriculum innovation in music. Proceedings of the 4th Asia-Pacific Symposium on Music Education Research (Hong Kong, Department of Creative Arts, The Hong Kong Institute of Education).

Hanley, B. \& Montgomery, J. (2002) Contemporary curriculum practices and their theoretical bases, in: R. Colwell \& C. Richardson (Eds) (2002) The new handbook of research on music teaching and learning (Oxford, MENC/Oxford University Press).

Hargreaves, D. J. (2002) Opening speech at the Centre for International Research in Music Education (CIRME) Launch-Special Day Conference, University of Surrey Roehampton, London, 8 February.

Hentschke, L. (1993) Musical development: testing a model in the audience-listening setting. Unpublished Ph.D., University of London, Institute of Education.

Hickey, M. (2002) Creativity research in music, visual art, theatre, and dance, in: R. Colwell \& C. Richardson (Eds) (2002) The new handbook of research on music teaching and learning (Oxford, MENC/Oxford University Press). 
LeBlanc, A., Fung, C., Boal-Palheiros, G. et al. (2002) Effect of strength of rhythmic beat on preferences of young music listeners in Brazil, Greece, Japan, Portugal and the United States, in: G. Welch \& G. Folkestad (Eds) (2002) A world of music education research. Proceedings of the 19th ISME Research Seminar (Göteborg, School of Music and Music Education, Göteborg University).

Lennon, M. (1996) Teacher thinking: a qualitative approach to the study of piano teaching. Unpublished Ph.D. thesis, University of London, Institute of Education.

Lepherd, L. (Ed.) (1995) Music education in international perspective: national systems (Toowoomba, Australia, USQ Press in association with Faculty of Arts, University of Southern Queensland).

MacDonald, R. A. R. \& Miell, D. (2000) Creativity and music education: the impact of social variables, International fournal of Music Education, 36, 58-68.

Markea, G. (2002) Teachers' perceptions of musicality and its contexts: a study of piano pedagogy in Athenian conservatories. Unpublished Ph.D. thesis, University of London, Institute of Education.

MENC (1998) Research publication/presentation code of ethics. Available online at: www.menc.org/publication/articles/jrmeethics.htm

Odena, O. (2001a) Developing a framework for the study of teachers' views of creativity in music education, Goldsmiths fournal of Education, 4(1), 59-67.

Odena, O. (2001b) The construction of creativity: using video to explore secondary school music teachers' views, Educate The London Fournal of Doctoral Research in Education, 1(1), 104-122.

Odena, O. (2001c) How do secondary school music teachers view creativity? A report on educators' views of teaching composing skills, paper presented at the Symposium 'Creativity in Education: Perspectives, Evaluations and Individual Development'. Available online at: www.leeds.ac.uk/educol/documents/00003133.htm

Odena, O. (2001d) How do teachers view creativity? A framework for the study of the music educators' perception of creativity, paper presented at the 2nd International Conference for Research in Music Education, University of Exeter, 6 April.

Odena, O. (2002) Using videotaped extracts of lessons during interviews to facilitate the eliciting of teachers' thinking. An example with music schoolteachers' perceptions of creativity, paper presented at the European Educational Research Association Annual Conference 2002, University of Lisbon, 12 September. Available online at: www.leeds.ac.uk/educol/ documents/00002206.htm

Odena, O. (2003) Creativity in music education with particular reference to the perceptions of teachers in english secondary schools. Unpublished $\mathrm{Ph} . \mathrm{D}$. thesis, University of London, Institute of Education.

Papapanayiotou, X. (1998) The acquisition of musical preferences: a study of three age groups in the social and cultural environment of Greece. Unpublished Ph.D. thesis, University of London, Institute of Education.

Rex, L., Murnen, T., Hobbs, J. \& McEachen, D. (2002) Teachers' pedagogical stories and the shaping of classroom participation: 'The dancer' and 'Graveyard shift at the 7-11', American Educational Research Fournal, 39(3), 765-796.

Savage, J. (2003) Informal approaches to the development of young people's composition skills, Music Education Research, 5(1), 81-85.

Silva, M. C. C. F. (1998) Composing, performing and audience-listening as symmetrical indicators of musical understanding. Unpublished Ph.D. thesis, University of London, Institute of Education.

Stavrides, M. (1995) The interaction of audience-listening and composing: a study in Cyprus schools. Unpublished Ph.D. thesis, University of London, Institute of Education.

Stevens, R. S. (2000) Where are we twenty years on? A review of Australian music education research for the period 1978-1997, Research Studies in Music Education, 14, 61-75. 


\section{O. Odena}

Swanwick, K. (1999) Teaching music musically (London, Routledge).

Swanwick, K. (2001) Musical development theories revisited, Music Education Research, 3(2), 227-242.

Swanwick, K. \& Franca, M. C. (1999) Composing, performing and audience-listening as indicators of musical understanding, British fournal of Music Education, 16(1), 5-19.

Totterdell, M. (2003) Intellectual property rights and doctoral studies. Invited speaker for the Doctoral School at the University of London Institute of Education, Nunn Hall, 14 May.

Upitis, R. (1999) Artistic approaches to research, Music Education Research, 1(2), 219-226.

Welch, G. (2002) 19th ISME Research Seminar-Research Commission Chairs' Report, Bergen. Available online at: www.isme.org/article/articleview/138/1/10 